\title{
Von christlichem Antijudaismus im modernen Antisemitismus
}

\section{Axel Töllner}

Eingegangen: 19. März 2021 / Überarbeitet: 7. Dezember 2021 / Angenommen: 27. Dezember 2021 /

Online publiziert: 15. Februar 2022

(C) Der/die Autor(en) 2022

Zusammenfassung Judenfeindschaft wird heute häufig mit dem Begriff Antisemitismus gleichgesetzt. Dies gilt sowohl im allgemeinen Sprachgebrauch als auch in wissenschaftlichen Diskursen. Daneben gibt es jedoch Stimmen, die für eine begriffliche Differenzierung plädieren, weil Ziele und Erscheinungsformen der Judenfeindschaft zu unterschiedlich seien, als dass sie unter einem einzigen Oberbegriff subsummiert werden könnten. Zugleich lässt sich beobachten, dass eine begriffliche Unterscheidung zwischen älterem (religiösem) Antijudaismus und modernem (säkularem) Antisemitismus mitunter auch apologetische Ziele verfolgt.

Der Artikel geht der Frage nach, ob und inwieweit ältere Antijudaismen bis heute relevant sind. Dabei soll anhand ausgewählter Beispiele gezeigt werden, dass sich die Entwicklungen und Transformationen von einer älteren, religiösen (meist christlichen) Judenfeindlichkeit zu einem modernen, säkularen Judenhass nicht in einem linearen Prozess vollzogen haben. Während sich bereits in christlich-spätantiken Texten säkulare antijüdische Stereotype finden, wirken auch in gegenwärtigen, scheinbar säkularen Kontexten christlich geprägte antijüdische Feindbilder und Denkmuster nach. Der Blick auf die Quellen soll verdeutlichen, dass Judenfeindschaft in der Regel ein komplexes System aus Feindbildern und Vorstellungen unterschiedlicher - religiöser und nichtreligiöser - Herkunft ist. Insofern versteht sich der Artikel auch als Plädoyer dafür, traditionellen, christlich geprägten und tradierten antijüdischen Stereotypen mehr Aufmerksamkeit zu widmen.

Schlüsselwörter Antijudaismus · Antisemitismus · Judenfeindschaft · Adversus Judaeos-Literature · Verschwörungsmythos/Verschwörungstheorie

\footnotetext{
Axel Töllner $(\bowtie)$

Institut für christlich-jüdische Studien und Beziehungen, Augustana-Hochschule Neuendettelsau, Neuendettelsau, Deutschland

E-Mail: axel.toellner@elkb.de
} 


\section{On Christian anti-Judaism and modern anti-Semitism}

Abstract Hatred toward Jews is nowadays often identified with the term antisemitism. Sometimes, in a more narrow sense, the term anti-semitism is used to describe anti-Jewish conspiracy theories, anti-modern and racist attitudes, especially from the 19th century onwards. The term anti-Judaism, then, is used to characterize older religious - mainly Christian-Judeophobia. This article suggests that there is no linear evolution from older religious forms of hatred towards Jews to modern secular or racist perceptions. It analyzes selected sources from different centuries which indicate for viewing Judeophobia as a complex phenomenon that incorporated stereotypes of primarily non-religious origins from the times of the church fathers onwards. The article suggests also to pay attention to traditional anti-Jewish stereotypes - mainly Christian-coined and -handed down-in the present.

Keywords Anti-Judaism · Anti-semitism · Judeophobia · Adversus-JudaeosLiterature $\cdot$ Conspiracy theory

\section{Zur Fragestellung}

Mit „Antijudaismus“ und „Antisemitismus“ tauchen in den Debatten um antijüdische Phänomene und Ideologien immer wieder zwei verschiedene Begriffe auf. Häufig stehen beide für zwei verschiedene Stadien in der Entwicklung des Judenhasses von den Ursprüngen im religiösen, christlichen Antijudaismus zu deren Säkularisierung im modernen, rassistischen Antisemitismus seit dem 19. Jahrhundert (vgl. Kampling 2010a). Daneben lässt sich beobachten, dass traditionelle, häufig in christlich-religiösen Kontexten geprägte und tradierte Judenbilder bis heute einen Einfluss darauf haben, wie jüdische Menschen, Identitäten und überhaupt das, was als ,jüdisch“ gilt, wahrgenommen werden (vgl. Holz 2017). ${ }^{1}$

Wie sich tradierte und neuere Formen der Judenfeindschaft genau zueinander verhalten und was gegenüber dem Antijudaismus neu ist am modernen Antisemitismus, ist ,eine der umstrittensten Fragen nicht nur der kritischen christlichen Selbstreflexion [...], sondern auch der historischen Antisemitismusforschung“ (Wiese 2017, S. 30).

Dieser Artikel geht davon aus, dass bestimmte Grundmuster über die Jahrhunderte hinweg weiterentwickelt und aktualisiert wurden. Dazu gehört insbesondere die Etablierung dualer Wertungen im Blick auf das Judentum in den ersten Jahrhunderten, als das entstehende Christentum das Judentum ,jeweils als Antithese zum christlichen Selbstbild“ definierte (Hoffmann 1990, S. 22). Dieses Schema wirkte

\footnotetext{
1 Die Berliner Linguistin und Antisemitismusforscherin Monika Schwarz-Friesel stellt in ihrer Studie zum Antisemitismus im digitalen Raum fest: „Die klassische Judenfeindschaft ist nach wie vor die primäre Basis des aktuellen Judenhasses, im Netz wird die epochenübergreifende Reproduktion judeophober Stereotype und Verschwörungsphantasien in Tausenden von Texten täglich transparent. Über $50 \%$ aller Antisemitismen in den großen Datensammlungen weisen klassische Stereotype auf." (Schwarz-Friesel 2020, S. 16).
} 
- und wirkt - darin nach, dass das ,Jüdische“2 bis heute vielfach ein Maßstab für „das Andere“ geblieben ist, von dem sich das eigene Selbstverständnis abhebt (vgl. Wiese 2017). Neben diesem Dualismus hat die christliche Tradition auch eine paradoxe „Doppelstruktur“ des antijüdischen Feindbilds etabliert, die etwa antisemitische Verschwörungsvorstellungen kennzeichnet. Demnach seien „die Juden“ besonders verachtenswert und zugleich außerordentlich gefährlich (Friedländer 1998, S. 98).

Es sollen Quellen vorgestellt werden, die dafür sprechen, dass Judenfeindschaft sich in der Regel in Mischformen artikuliert und dass traditionelle, meist in der christlichen Tradition tradierte antijüdische Muster und Stereotype auch heute noch eine wichtige Rolle bei judenfeindlichen Einstellungen spielen (vgl. Wiese 2017). Der Artikel plädiert deshalb dafür, den traditionellen Elementen besondere Beachtung zu schenken.

\section{Christlicher Antijudaismus als komplexes Phänomen}

Bereits in den ersten Jahrhunderten nutzten altkirchliche Theologen in ihrer Polemik gegen konkurrierende Gruppen teilweise antijüdische Vorstellungen, die über den rein religiösen Bereich hinausgingen. So lassen sich hier judenfeindliche Verschwörungserzählungen, Neidvorstellungen oder die Unterstellung negativer moralischer Verhaltensweisen finden. Das Beispiel eines Textes aus dem späten 4. Jahrhundert soll das zeigen. Sein Verfasser Johannes Chrysostomus, später Bischof von Konstantinopel, gilt als Kirchenvater und sein Werk genießt bis heute hohe Wertschätzung und Autorität. Als Presbyter hielt er in den Jahren 386/387 in Antiochia insgesamt „Acht Reden gegen Juden“33, die verschiedenste Stereotype aus der antijüdischen Polemik in der Alten Kirche versammeln und deshalb mitunter als eine Art Kompendium für das verstanden werden, was christliche Theologen in den ersten Jahrhunderten der christlichen Zeitrechnung über jüdische Menschen und das Judentum zu wissen glaubten (vgl. Brändle und Jegher-Bucher 1995; Ritter 2017). Für die „Reden" des Johannes gilt wie für viele antijüdische Schriften christlicher Theologen, dass sie sich nicht an ein jüdisches Publikum richteten und auch keine Auseinandersetzung mit diesem führen wollten (vgl. z. B. Heil 2017; Kaufmann 2014). Vielmehr kritisierte Johannes innerchristliche Abweichlerinnen und Abweichler und warnte sie vor zu engen Kontakten und gemeinsamen religiösen Feiern mit der jüdischen Gemeinschaft in Antiochia. Dabei fällt auf, wie extrem scharf seine antijüdischen

\footnotetext{
2 Die Anführungszeichen sollen zum Ausdruck bringen, dass es sich hier um Projektionen handelt und nicht um reale jüdische Menschen und ihre Praktiken.

3 Unter diesem Titel erschien 1995 die kommentierte deutsche Übersetzung der Reden „Adversus Judaeos orationes" von Rudolf Brändle und Verena Jegher-Bucher. Zur Rezeption und Textüberlieferung der Reden vgl. Brändle und Pradels (2008).
} 
Ausfälle teilweise formuliert waren (vgl. Brändle und Jegher-Bucher 1995). ${ }^{4}$ Der Gegensatz zwischen christlichem und jüdischem Glauben war, wie aus den Reden selbst hervorgeht, im späten 4. Jahrhundert keineswegs allen Christen und Juden plausibel. Das Judentum in Antiochia erscheint als ausgesprochen vital, attraktiv und offen für die Teilnahme von Christen (vgl. Brändle und Jegher-Bucher 1995, S. 63f.; Kinzig 2002, S. 21; Ritter 2017, S. 36f.).

Drei Grundmuster der Judenfeindschaft lassen sich in den „Reden“ des Johannes zeigen: (1) Die Polemik beschränkt sich nicht auf die Feststellung religiöser Differenz, sondern sie behauptet auch darüber hinausgehende Eigenschaften oder Verhaltensweisen, die dem Selbstbild der eigenen Gruppe widersprechen. (2) Als Gegenbild zu ,den Christen“ und der von ihnen geforderten Lebensweise markiert Johannes eine bestimmte Gruppe sowie deren Glauben und Praktiken als ,jüdisch“. (3) Dabei unterstellt Johannes „,den Juden“ zugleich Schwäche und Macht.

Gemeinsam begegnen diese drei Grundmuster in einer Passage der 387 veröffentlichten polemischen Schrift „Demonstratio contra Judaeos et gentiles, quod Christus sit Deus“, die zeitlich und inhaltlich in engem Zusammenhang mit den „Reden“ steht (vgl. Migne 1862, S. 813-883; Schreckenberg 1982; Brändle und Jegher-Bucher 1995). Johannes stellt in dieser Schrift das Scheitern aller Bemühungen ,der Juden“, den Tempel nach seiner Zerstörung im Jahr 70 wieder zu errichten, der Macht Christi gegenüber, die Kirche zu gründen und deren Aufstieg zu ermöglichen:

Verfügen jene nicht über eine große Menge Geld? Besitzt nicht der Patriarch unermessliche Schätze, weil er von allen [und] überall Abgaben sammelt? Ist jenes Volk nicht unverschämt? Ist es nicht schamlos, streitsüchtig, unbesonnen, aufrührerisch? Sind sie nicht zahlreich in Palästina? Sind sie nicht zahlreich in Phönizien? Sind sie nicht zahlreich überall? Wie also brachten sie es nicht zuwege, den einen Tempel wieder zu errichten, zumal als sie sahen, dass ihr Gottesdienst von da an überall behindert ist, dass die jüdischen Riten, Opfer, Opfergaben und die übrigen derartigen Gesetzlichkeiten aus der Welt geschafft sind und gänzlich brachliegen? (Migne 1862, S. 834f.) ${ }^{5}$

Zwar versucht Johannes hier in erster Linie zu beweisen, dass Gott sich vom Judentum abgewandt und der Kirche zugewandt hat. Doch beinhaltet diese theologische Substitutionsvorstellung (vgl. Kampling 2010b) zugleich eine politische

\footnotetext{
${ }^{4}$ Wenngleich Johannes nach den damaligen rhetorischen Gepflogenheiten auch gegenüber christlichen Abweichlern ausgesprochen scharf werden konnte, so überschritt er im Blick auf das Judentum sämtliche Grenzen. So diffamierte er die Synagoge, die etliche Christen hoch schätzten und regelmäßig besuchten, als „Hurenhaus“, „Räuberhöhle“, „Zufluchtsstätte unreiner Tiere“ oder „Wohnstätte der Teufel“ (Brändle und Jegher-Bucher 1995, S. 55). Und genauso beleidigend und wahrheitswidrig unterstellte Johannes, dass Juden kollektiv „für ihren Bauch leben, nach dem Gegenwärtigen gieren, nicht besser als Schweine und Böcke, was ihre Haltlosigkeit anbetrifft und ihre grenzenlose Völlerei“" (Brändle und Jegher-Bucher 1995, S. 90).

5 Auch in den „Reden“ bezieht Johannes sich auf die Zerstörung des Jerusalemer Tempels. Ganz in den Bahnen der Tradition deutet er sie als Sühne für der Schuld ,der Juden“ am Tod Jesu. Zugleich sieht er die gescheiterten Bemühungen um die Wiedererrichtung der Tempels als Beleg für die Verwerfung ,der Juden" durch Gott und ihre Ersetzung durch die christliche Kirche (vgl. Schreckenberg 1982, S. 320-329, hier 323f.).
} 
Dimension. So deutet Johannes den im Laufe des 4. Jahrhunderts erfolgten - und damals nach wie vor teilweise fragilen - Aufstieg des Christentums zur Staatsreligion geschichtstheologisch als Beleg für die religiöse Enterbung des Judentums. Der Bedeutungszuwachs der christlichen Gemeinschaft zum politischen und gesellschaftlichen Machtfaktor im Römischen Reich galt ihm als sichtbarer Beweis dafür, dass Gott sein Urteil über die Glaubens- und Lebensweise der Juden besiegelt und seine Gunst endgültig von ihnen abgezogen habe. Folglich gingen nach dem Verständnis des Johannes die theologische Würde des jüdischen Volks als Gottesvolk sowie seine Aussichten auf ein eigenes Gemeinwesen gleichermaßen verloren und auf Christus mit seiner Kirche über. Deren sichtbar gewachsener Einfluss war für Johannes zugleich der Beleg für die Richtigkeit der eigenen christlichen Glaubensüberzeugungen und die Verkehrtheit der jüdischen.

Es fällt auf, dass Johannes mit den Stereotypen vom angeblichen Reichtum, der Macht, Größe und Illoyalität ,,jenes Volk[es]“ jüdischen Menschen Eigenschaften zuschreibt, die nicht primär religiös konnotiert sind. Folgerichtig gründen die gegen das Judentum gerichtete Profilierung, Abgrenzung und Vergewisserung des christlichen Glaubens zwar wesentlich im kirchlich-religiösen Kontext, erschöpfen sich aber nicht darin. Die Verschmelzung von religiösen und nicht-religiösen Stereotypen lässt sich nicht nur bei Johannes beobachten, sondern zeigt sich auch in späterer Zeit immer wieder (vgl. Schüler-Springorum 2018, S. 365f.). Womöglich hat gerade auch die Durchlässigkeit von christlich-antijüdischen Vorstellungen für Ressentiments und Verschwörungsvorstellungen unterschiedlicher Herkunft dazu beigetragen, die Judenfeindschaft über die Jahrhunderte hinweg wandlungsfähig zu halten und ihre scheinbare Plausibilität zu erklären (vgl. Junginger 2011, S. 22; Heil 2017, S. 38-42; Wiese 2017, S. 29; Schäfer 2020, S. 95-100).

Christlich motivierte antijüdische Vorstellungen führten nicht nur zu einer kritischen Bewertung oder Ablehnung der Lebensführung und Überzeugungen jüdischer Menschen. Sie begründeten auch keine rein akademisch-theoretische Judenfeindlichkeit. So wurzelt das Konzept der „,bedingten Toleranz“, das die Rechtsstellung der jüdischen Minderheit im christlichen Europa bis weit in das 19 Jahrhundert maßgeblich beeinflusste, in einer theologischen Konzeption, wie sie im späten 4. und frühen 5. Jahrhundert der Kirchenvater Augustinus von Hippo maßgeblich formuliert hatte. Dieses Konzept der „,bedingten Toleranz“ ermöglichte die Duldung einer nichtchristlichen Minderheit in einer christlichen Gesellschaft unter einem spezifischen Sonderrecht und mit einem niedrigeren Rechtsstatus. Theologisch liegt ihm die Überzeugung zugrunde, dass jüdische Menschen zwar ihren Ungehorsam gegenüber Gott demonstrierten, indem sie sich der christlichen Wahrheit verweigerten und eine falsche Religion praktizierten, aber als Angehörige des einst auserwählten Volkes zugleich die Heiligen Schriften des Alten Testaments überlieferten und Gott selbst das abschließende Urteil über das jüdische Volk und seinen vermeintlichen Ungehorsam bzw. Abfall vom wahren Glauben zustehe (vgl. Kampling 2010a; Heil 2017; Kirn 2017; Ritter 2017). Das jüdische Sonderrecht und das Konzept der ,,bedingten Toleranz" konnten zwar phasenweise eine gewisse Rechtssicherheit bieten, von verschiedenen Obrigkeiten an unterschiedlichen Orten und zu unterschiedlichen Zeiten strenger oder großzügiger gehandhabt werden und so Spielräume für die jüdische Gemeinschaft und einzelne Juden und Jüdinnen eröffnet haben. Doch 
insgesamt handelte es sich um ein restriktives Regelwerk, das für die überwiegende Mehrheit der jüdischen Bevölkerung prekäre Lebensumstände bewirkte. Gegen die immer wieder aufflammende Gewalt und die Aktualisierung antijüdischer Einstellungen oder Verschwörungsvorstellungen erwies sich das Schutzversprechen der „,bedingten Toleranz“ insgesamt als zu schwach und brüchig (Heil 2017; Kirn 2017). Insofern sollte „Antijudaismus“, verstanden als traditionelle Judenfeindschaft, nicht gegenüber dem modernen „Antisemitismus“ bagatellisiert werden (vgl. Wiese 2017).

\section{Die Juden als Antithese zu allen anderen Menschen}

Den modernen Antisemitismus kennzeichnet unter anderem die Überzeugung, dass „das Judentum“ bzw. das jüdische Kollektiv nicht einfach nur ein Gegenüber der eigenen Gruppe etwa zu anderen Völkern darstellt, sondern gewissermaßen die Antithese zu allen Menschen schlechthin (vgl. Holz 2001). Die Vorstellung, dass „die Juden“ nicht allein ein äußerer Feind seien, sondern vielmehr die Identität der eigenen Gruppe von innen her gefährdeten, lässt sich allerdings bereits in vormodernen Zusammenhängen nachweisen und bis in die vorchristliche Antike zurückverfolgen (Schäfer 2020, S. 26-28). ${ }^{6}$ Dabei weckte etwa der Umstand Argwohn und Hass, dass Juden nicht nur in einer bestimmten Region bzw. einem einzigen Land lebten, sondern in verschiedenen nichtjüdischen Mehrheitsgesellschaften ihre jüdische Identität aufrecht erhielten. Das biblische Buch Ester enthält Hinweise darauf, dass diese Diasporaexistenz bereits in der Antike Vernichtungsfantasien gegen das jüdische Volk insgesamt auslösen konnte (Schäfer 2020, S. 24f.). ${ }^{7}$

Später wurden religiöse Abweichler in der christlichen Welt regelmäßig als ,Judaisierer“ oder heimliche „Juden“ bezeichnet und mitunter galt das Judentum sogar als Prototyp aller Abweichungen vom wahren Glauben (Heil 2017, S. 35). Geradezu inflationär musste das jüdische Feindbild in innerchristlichen Debatten um Rechtgläubigkeit und Abweichung als Maßstab für den Abfall vom (wahren) Glauben herhalten (Vgl. ebd. und Heil 2006). In der Reformationszeit, die in besonderer Weise von solchen Debatten gekennzeichnet war, unterstellten sich Altgläubige und Anhänger der Reformation gleichermaßen, die jeweils anderen würden ,judaisieren“, seien ,jüdisch“ etc. So behaupteten Reformatoren, die Altgläubigen hingen durch ihre Riten der Häresie einer vermeintlich ,,jüdischen“ Gesetzlichkeit an. Andererseits erweckte etwa die Hinwendung der Reformatoren zur hebräischen Sprache den Argwohn Altgläubiger. Aber auch innerhalb der reformatorischen Bewegung sahen sich bestimmte Gruppen oder Personen Vorwürfen ausgesetzt, „Judaismus“ - im

\footnotetext{
${ }^{6}$ Dies zeigt sich etwa, wenn der ägyptische Pharao nach Ex 1,9-10 unterstellt, dass das Volk Israel ,,mehr und stärker als wir“ sei, und deshalb plant, die Israeliten ,mit List niederzuhalten“. Denn sollten sie noch zahlreicher werden, drohe die Gefahr, dass ,,sie sich auch zu unsern Feinden schlagen und gegen uns kämpfen".

7 Nach Est 3,8-10 kann der persische Großwesir Haman seine Ausrottungsfantasien allein mit dem Hinweis darauf plausibel machen, dass das jüdische Volk überall im Reich ,,verstreut und abgesondert“ lebe und die Angehörigen dieses Volkes ein Gesetz befolgten, das ,anders als das aller Völker“ sei. Haman suggeriert dem König deshalb, dass die Juden grundsätzlich illoyal seien und „nicht nach des Königs Gesetzen" handelten.
} 
Sinne von jüdischer Irrlehre - zu praktizieren (vgl. Detmers 2001, 2002, S. 76-81; Heil 2006, S. 324-355; Kaufmann 2011, S. 29-42, 2014, S. 67f.). ${ }^{8}$ Eine Aussage des Züricher Reformators Huldrych Zwingli in einer Predigt aus dem Jahr 1530/1531 deutet auf eine weite Verbreitung dieser Praxis hin: „Wie wir es noch heute sehen können, welch grosser Schimpf der Judenname ist, so dass wir die, die wir mit der grössten Schmähung behaften möchten, Juden nennen.“ (zit. n. Detmers 2001, S. 160).

Seit dem Mittelalter sahen sich Konvertiten wiederholt dem Generalverdacht ausgesetzt, es mit ihrer Konversion nicht ernst gemeint zu haben oder nur über geringen Glauben zu verfügen. Auf diesem Weg würden sie ,jüdische“ Irrlehren und Riten in die Kirche eintragen und sie so von innen heraus schwächen. Insbesondere seit dem 13. und 14. Jahrhundert verbanden sich mit solchen Unterstellungen auch Verschwörungsvorstellungen von einer planmäßigen Unterwanderung der christlichen Lehre und der christlichen Gemeinschaft durch Konvertiten. Insofern ist es nicht verwunderlich, dass in den Auseinandersetzungen um Rechtgläubigkeit und innerchristliche Glaubensabweichung der Reformationszeit die Figur des jüdischen Konvertiten bzw. des ,Judaisierers“ regelmäßig als Instrument einer Verschwörung gegen die Christen auftaucht (vgl. Heil 2006; Detmers 2001; Morgenstern 2016).

\section{Christliches in zeitgenössischen Formen der Judenfeindschaft}

In den letzten Jahren und Jahrzehnten wird zunehmend sichtbar, dass die Muster der traditionellen christlichen Judenfeindschaft nicht überwunden sind. Trotz vielfältiger Bemühungen der Kirchen um eine Abkehr von der Judenfeindschaft lassen sich bei christlich und kirchlich gebundenen Menschen antijüdische Einstellungen nicht seltener finden als bei Menschen, die sich als nicht religiös verstehen (vgl. Scherr 2011; Lobermeier et al. 2016). Auch in der wissenschaftlichen Theologie oder in Schulbüchern für den Religionsunterricht, wo antijüdische Muster lange Zeit beherrschend waren, finden sich noch Spuren des überkommenen Denkens (vgl. Blum 2010a; Spichal 2015).

Antijudaismus und Antisemitismus sind komplexe und dynamische Phänomene, die sich gegenseitig beeinflussen und überlappen (vgl. Schäfer 2020; SchwarzFriesel 2020). Die Tradition liefert ein umfangreiches Reservoir für gegenwärtige Artikulationen von Feindseligkeit und Hass gegen Juden sowie für verzerrte Wahrnehmungen des Judentums, jüdischer Lebensweisen und Menschen (vgl. z. B. Scherr 2011; UEA 2011, 2017; Lobermeier et al. 2016; Schwarz-Friesel 2020). Auch moderne Antisemitismen, die für sich einen säkularen, rationalen Zugriff in Anspruch

\footnotetext{
8 Dies galt etwa für die Täufer, die eine besondere Affinität zu alttestamentlichen Lehren hatten, oder die christlichen Hebraisten, die sich intensiv mit jüdischen Schriften beschäftigten (vgl. Detmers 2001). Unterschiedliche hermeneutische Zugänge zur Bibel oder die Beschäftigung mit hebräischen Schriften und jüdischen Überlieferungen waren zwar die konkreten Auslöser. Doch die Schärfe der Diffamierungen und Anfeindungen lässt sich damit allein nicht erklären. Sie wurzelte vielmehr in der Furcht, die betreffenden Personen brächten durch ihre (scheinbare oder tatsächliche) Nähe zu Praktiken oder ihre Beschäftigung mit Schriften, die als ,,jüdisch“ galten, die christliche Lehre ernsthaft in Gefahr (vgl. Detmers 2001; Heil 2006; Kaufmann 2011, 2014).
} 
nehmen, bedienen sich nötigenfalls christlich geprägter Motive (vgl. Junginger 2011; Treß 2018).

\subsection{Post-Schoah-Aktualisierungen des Antijudaismus im ,Wort zur Judenfrage" 1948}

Traditionelle, theologische Antijudaismen können weiterhin aktuelle Denkmuster integrieren, die keinem primär religiösen Ursprung entspringen. Für die Zeit nach 1945 gilt dies beispielsweise für die nach der Schoah entstandene Form des schuldabwehrenden „sekundären“ Antisemitismus. Dies zeigt sich etwa im Kontext der Nachkriegsdebatten um Schuld und Verantwortung im Blick auf die Schoah, als sich mit dem Bruderrat der Evangelischen Kirche in Deutschland ein leitendes Gremium des deutschen Protestantismus in seinem „Wort zur Judenfrage“ vom 8. April 1948 äußerte. Im Einklang mit weiten Teilen der theologischen Tradition erklärten hochrangige Vertreter der evangelischen Kirchen „Israel“, das „den Messias kreuzigte“, zum Inbegriff des „Widerspruch[s] aller Menschen und Völker gegen den Christus Gottes“ (zit. n. Rendtorff und Henrix 1988, S. 542). Vordergründig wiederholte der „Bruderrat“ klassische Topoi der christlichen Judenfeindschaft. Doch der besondere Akzent dieser Kundgebung liegt anderswo: „Israel unter dem Gericht ist die unaufhörliche Bestätigung der Wahrheit, Wirklichkeit des göttlichen Wortes und die stete Warnung Gottes an seine Gemeinde. Daß Gott nicht mit sich spotten läßt, ist die stumme Predigt des jüdischen Schicksals, uns zur Warnung, den Juden zur Mahnung, ob sie sich nicht bekehren möchten zu dem, bei dem allein ihr Heil steht." (zit. n. ebd.).

Irritierend ist heute nicht nur, dass der Bruderrat der EKD scheinbar unberührt von der Schoah in den Bahnen der christlichen Judenfeindschaft weiterredete, sondern deren Muster aus der Post-Schoah-Perspektive aktualisierte. So relativierte und bagatellisierte er die deutsche und christliche Mitschuld an der Schoah nicht nur, sondern vollzog mit seiner geschichtstheologischen Deutung eine Täter-Opfer-Umkehr. Letztlich verorteten die hochrangigen Vertreter des deutschen Protestantismus die Schuld an der Vernichtung bei den jüdischen Opfern selbst, weil „Israel den Messias kreuzigte“ (vgl. Töllner 2020, S. 426-428).

Damit bildet die Erklärung eine theologisch verbrämte Blaupause für die verschiedenen Formen, in denen sich seit 1945 die Verdrängung und Abwehr von Schuld und Verantwortung im Post-Schoah Antisemitismus entfaltet, sei es in subtilen Bagatellisierungen oder gar Leugnungen der Schoah, sei es in den Versuchen einer Täter-Opfer-Umkehr, sei es in der Sehnsucht nach einem Schlussstrich (vgl. z.B. Bergmann 2010; UEA 2017, S. 26f.).

\subsection{Christliches im Verschwörungsmythos vom „König Rothschild““}

Abb. 1.

Eine Karikatur des französischen Zeichners Charles Léandre (1862-1934) aus dem Satiremagazin „Le Rire“ vom 16. April 1898 trägt die Überschrift „Le Roi Rothschild" - der König Rothschild. Die Publikation fiel in eine in Frankreich hochgradig aufgeladene Phase, in der sich massive revanchistische, autoritäre, na- 
Abb. 1 Le Roi Rothschild (Der König Rothschild). Antisemitische Karikatur von Charles Lucien Léandre (1862-1934) auf der Titelseite der Zeitschrift Le Rire v. 16.04.1898. (https:// commons.wikimedia.org/wiki/ File:Antisemiticroths.jpg. Public Domain. Zugegriffen: 2. Dezember 2021)

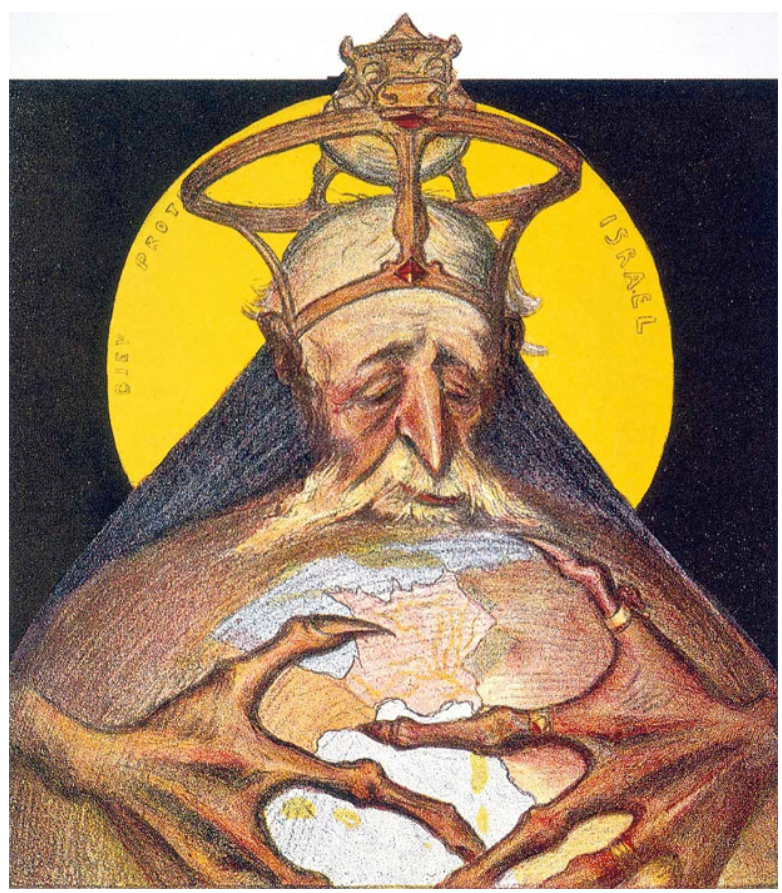

tionalistische und antisemitische Reflexe offenbarten und Verschwörungslegenden Hochkonjunktur hatten. 1886 hatte der Journalist Édouard Drumont mit La France Juive einen mehrfach übersetzten Bestseller veröffentlicht, der zum wichtigsten Werk des modernen französischen Antisemitismus avancierte, und seit 1894 verdichteten sich all diese antimodernen Ressentiments in der antisemitischen Dreyfus-Affäre, die nicht zuletzt von königstreuen katholischen Kreisen angeheizt wurde (vgl. Holz 2001, S. 298-302; Harket 2019; Schäfer 2020, S. 224f.).

Auf Léandres Zeichnung ist Baron Alphonse de Rothschild (1827-1905) zu sehen, der sich als sogenannter König Rothschild - Roi Rothschild - mit teuflisch langen und knochigen Fingern der Welt bemächtigt. Der Name der ursprünglich aus Frankfurt stammenden Familie Rothschild galt seit dem frühen 19. Jahrhundert als Inbegriff des mächtigen jüdischen Bankiers (Lange 2010). Noch heute fungiert er ungebrochen als Chiffre für das vermeintlich jüdisch dominierte Finanzkapital, das darauf aus sei, die kleinen Leute auszubeuten, als „graue Eminenz“ hinter Krisen, Kriegen, Katastrophen (vgl. Schwarz-Friesel 2020; RIAS Bayern 2021). Wer „Rothschild" sagt, kann seit dem 19. Jahrhundert in vielen Fällen davon ausgehen, dass der Adressatenkreis die judenfeindlichen Absichten dahinter versteht. ${ }^{9}$

\footnotetext{
9 So identifizierte der mit christlich-apokalyptischen Motiven spielende Sänger Xavier Naidoo 2009 in seinem Lied „Raus aus dem Reichstag“ ziemlich unverhohlen einen „Baron Totschild“ als einen der tonangebenden Hintermänner all dessen, was er als politisches Versagen der deutschen Regierung im Berliner Reichstag identifizierte (zit. nach https://genius.com/Xavier-naidoo-raus-aus-dem-reichstag-lyrics. Zugegriffen: 15. März 2021).
} 
Léandre illustrierte 1898 den verbreiteten Verschwörungsmythos, der suggeriert, reiche Juden hätten die Welt in der Hand und beherrschten sie. Darüber hinaus enthält seine Zeichnung Anspielungen auf Bildtraditionen aus der christlichen Kunst, die im katholisch geprägten Frankreich vorhandene christlich-antijüdische Ressentiments bedienen konnte. Die Darstellung weist dabei die charakteristische paradoxe Doppelstruktur der Judenfeindschaft auf: So kann sich einerseits in dem greisenhaftmüde dargestellten „Roi Rothschild“ der traditionelle christliche Triumphalismus wiederfinden, der das Judentum für veraltet, überholt und kraftlos erklärt. Andererseits schreibt die Darstellung diesem vergreisten König Rothschild sagenhafte, geradezu dämonische Macht über die ganze Welt zu. Die Auszeichnung mit einem Heiligenschein betont seine übermenschlichen Fähigkeiten, hebt der Nimbus doch in der christlichen Kunst besondere Personen über den Status normaler Menschen hinaus und schreibt ihnen besondere Fähigkeiten und Kräfte zu. Die Darstellung bedient sich bereits formal der Bildsprache der christlichen Kunst, bei näherem Hinsehen zeigt sich außerdem, dass der Nimbus eine religiös konnotierte Inschrift trägt: „Dieu protège Israël“ - Gott schütze Israel. Oben auf der Krone des Königs Rothschild präsentiert die Zeichnung diesen Gott als Goldenes Kalb. Dabei handelt es sich um ein traditionelles antijudaistisches Motiv, das „das Judentum“ als religiöses und moralisches Gegenbild zum Christentum konstruiert: Dem wahren Gott des Christentums mit seinen geistlichen, ewigen Werten steht in diesem Modell gewissermaßen das vom wahren Glauben abgefallene Judentum mit seinem Abgott und seinen materiellen, weltlichen Werten gegenüber (vgl. Schreckenberg 1996, S. 116-121; Kampling 2010b, S. 312; Heil 2015, S. 347). Neben dem Goldenen Kalb konnten auch die überzeichneten körperlichen Merkmale des Königs Erinnerungen an christliche Bildtraditionen wecken, die seit dem Mittelalter Personen mit Hakennase, wulstigen Ohren oder betonten Augenlidern als ,jüdisch“ markierten (vgl. Schreckenberg 1996; Enzenbach 2018). Die Anknüpfung an bekannte Stereotype und vertraute Muster schrieb diese nicht nur aktualisierend fort, sie dürfte auch den Eindruck beim Publikum verstärkt haben, dass hier etwas erzählt wird, was glaubwürdig ist und was man über ,die Juden“ wissen kann (vgl. Heil 2006, S. 14). ${ }^{10}$

\subsection{Bewusst und unbewusst antijüdische Kontrastfolien: Schlaglichter auf ein wiederkehrendes Muster}

Eine antijüdische Äußerung muss nicht unbedingt absichtlich und gezielt feindselig, verletzend oder gewalttätig sein. Judenfeindliche Stereotype, Denkfiguren, Bilder und Redeweisen sind im kommunikativen oder kulturellen Gedächtnis der europäischen Gesellschaften verfügbar und können sowohl bewusst als auch ungewollt

\footnotetext{
10 Johannes Heil urteilt hier im Blick auf die „Protokolle der Weisen vom Zion“: „Der Vergleich deutet aber auch an, daß nicht der Inhalt allein den Erfolg solcher Narrative erklärt. Voraussetzung war und ist, daß die darin ausgestaltete Denkfigur in ihren Grundzügen ihrerseits schon verbreitet war. So hat dann auch das moderne Machwerk russisch-französischer Judenfeinde und seiner deutschen Multiplikatoren nicht erst Anhängerschaft geschaffen, sondern diese nur bedient.“ (2006, S. 14) Aus meiner Sicht spricht einiges dafür, dass sich diese Interpretation auch auf andere antisemitische Erzählungen wie etwa die vom „Roi Rothschild“ übertragen lässt.
} 
weitertradiert werden. Das heißt, auch wenn antijüdische Konnotationen bestimmter Redensarten, Begriffe oder Stereotypisierungen nicht bekannt sind und eine Äußerung ohne antijüdische Absicht erfolgt, können damit Ressentiments, Zerrbilder und Zuschreibungen aus dem Reservoir der Judenfeindschaft fortgeschrieben werden (vgl. z. B. Schwarz-Friesel und Reinharz 2013, S. 49f.; Zick et al. 2017).

Das bedeutet, dass der antijüdische Gehalt eines bestimmten Begriffs oder einer Denkfigur nicht erkannt werden oder unhinterfragt bleiben kann. So wird etwa der Begriff „Pharisäer“ bzw. ,pharisäerhaft“ häufig klischeehaft verzeichnet. In vielen Fällen ist den Personen, die dieses Klischee bedienen, wohl keine antijüdische Absicht zu unterstellen. Trotz allem leisten solche ,nicht intentionale[n] Alltagsantisemitismen“ ungewollt einen Beitrag zur Stabilisierung und weiteren Verbreitung von traditionellen antijüdischen Stereotypen und Mustern (Schwarz-Friesel 2020, S. 21).

Unter „Pharisäer“ wird etwa nach der Online-Fassung des „Duden“ ein „Angehöriger einer altjüdischen, die religiösen Gesetze streng einhaltenden Bewegung“ verstanden, eine ,,selbstgerechte männliche Person; Heuchler“ oder ein Heißgetränk, das „,den Anschein erwecken“ solle, ,man trinke keinen Alkohol, sondern nur Kaffee“. Verwendet werde der Begriff ,gehoben abwertend“ (duden.de: Zugegriffen am 26. November 2021). Analog verzeichnet der Duden für das Lemma ,pharisäerhaft““ die Synonyme „heuchlerisch“, ,scheinheilig“, „unehrlich“ und „unlauter“ (ebd.). Das mag einem verbreiteten Sprachgebrauch entsprechen, doch aus dem Eintrag wird nicht ersichtlich, dass dieser Sprachgebrauch auf einer polemischen Verzeichnung durch neutestamentliche Autoren beruht, die mittlerweile in der theologischen Forschung und in kirchlichen Dokumenten vielfach als unsachgemäß problematisiert wird (vgl. Spichal 2015; Wiese 2019). Die christliche Tradition markiert ,die Pharisäer" häufig eindeutig negativ als Inbegriff der Gegner und Verfolger Jesu sowie der ersten Christusgläubigen (vgl. Blum 2010a). Wo Pharisäer als Verkörperung des antijüdischen Stereotyps vom ,macht- und geldgierigen Juden“ gelten, drohen sich die Feindbilder zu überlagern und zu verstärken (vgl. Blum 2011). In der bildenden Kunst und der Theologie, im Religionsunterricht und in volkstümlichen Bräuchen wie Passionsspielen zeigt sich, wie das antipharisäische und das antijüdische Feindbild verschmelzen können (vgl. Schreckenberg 1996; Blum 2010a, 2011; Spichal 2015). Es wäre im Einzelnen zu prüfen, inwieweit dieses antipharisäische Zerrbild das Bild der Juden als ,der Anderen“ in der christlichen Mehrheitsgesellschaft seit dem Mittelalter mitgeprägt hat. Da sich das gegenwärtige Judentum religiös und kulturell auf seine pharisäisch-rabbinischen Traditionen bezieht, besteht die realistische Gefahr, dass antipharisäische Stereotype und Klischees auf Jüdinnen und Juden übertragen werden (Spichal 2015, S. 203-209).

Wie sich in der theologischen Wissenschaft beides vermischen konnte, sei am Beispiel der Broschüre ,Jesus und die Rabbinen“ aus dem Jahr 1914 illustriert. Verfasst hatte sie am Anfang seiner akademischen Karriere der später weltweit geachtete evangelische Theologe und Judaist Gerhard Kittel, der in der NS-Zeit zu einem der führenden „Judenforscher“ wurde (vgl. Junginger 2011; Gailus und Vollnhals 2020). Für Kittel war „der Gegensatz“ zwischen Jesus und seinen jüdischen schriftgelehrten Zeitgenossen so fundamental, dass er ,ihm den Tod gebracht“ habe (zit. n. Reinbold 2013, S. 307). Der Begründer des epochalen und lange Zeit international maß- 
geblichen „Theologischen Wörterbuchs zum Neuen Testament“ würdigte auf der einen Seite das Wirken Jesu als ,lebendige [...] Reich-Gottes-Arbeit“ und diffamierte zugleich das der Rabbinen als ,totes Gesetzesstudium und Gelehrtentum“ (zit. n. ebd.). Diesen gestand er zwar auch eine gewisse „Moral und Sittlichkeit“ zu (zit. n. Lindemann 2020, S. 69), doch im Ganzen verzeichnete Kittel die Diskussionen der Rabbinen zu einer länglichen „Ausklügelung aller schmutzigen Möglichkeiten“, mithin zum Gegenteil der knappen, „reinen, klar leuchtenden Sätze [...]“, mit denen Jesus ,die ganze Sittlichkeitsfrage erledigt“ habe (zit. nach Reinbold 2013, S. 307).

Ähnliches lässt sich etwa in dem Muster erkennen, das einen Gegensatz zwischen dem scheinbar veralteten Judentum und dem scheinbar zeitgemäßen Christentum konstruiert. Bereits in der Zeit zwischen 160 und 170 der allgemeinen Zeitrechnung setzte Bischof Meliton von Sardeis in seiner Osterpredigt ,,peri pascha“ eine solche Polarität von Judentum und Christentum voraus. In der Geschichte der christlichen Judenfeindschaft nimmt diese Quelle insofern eine bedeutsame Rolle ein, als sie den ersten bekannten literarischen Beleg für den Gottesmordvorwurf darstellt und das folgenreiche antijüdische Stereotyp der Juden als „Gottesmörder“ begründete (vgl. Blum 2010b). Während diese Kollektivbeschuldigung in den meisten christlichen Kirchen des Westens nicht mehr offiziell vertreten wird, wirkt ein anderer Argumentationsstrang innerhalb und außerhalb der Kirchen weiter, wenn auch selten so unverblümt wie bei Meliton. Der Bischof von Sardeis verbindet seinen unmissverständlichen und exklusiven Wahrheitsanspruch für das Christentum mit der abwertenden Behauptung, Israel sei bloßes Vorbild gewesen und nunmehr von der Kirche abgelöst: ,[S] eit die Kirche erstand und das Evangelium vorgelegt wurde, wurde das Vorbild entwertet und übergab seine Kraft an die Wahrheit [...] und das Volk (Israel) wurde entwertet durch das Erstehen der Kirche, [...] Und heute ist das, was einst wertvoll war, wertlos geworden durch die Offenbarung des wesenhaft Wertvollen“ (zit. nach Schreckenberg 1982, S. 202f.).

Antijüdische Sprachmuster wie diese treten nicht allein an den Rändern der Gesellschaft auf und sie sind keine Frage des Bildungsabschlusses oder des bösen Willens. Solche Muster können wie gesagt auch völlig unbeabsichtigt reproduziert werden und sogar ohne das Wort „Jude“ selbst auskommen (vgl. Schwarz-Friesel und Reinharz 2013, S. 1f., 26 und 109f.). Diese Problematik kann vielleicht ein Blick auf einen Artikel der Schriftstellerin, Theaterautorin und Journalistin Jagoda Marinić erhellen. In ihrer Kolumne der „Süddeutschen Zeitung“ vom 21. April 2019 versucht sie angesichts des nahen Osterfestes das Nachdenken über männliche Rollenbilder in einen religiösen Kontext zu rücken. Dabei überträgt Marinić das Stereotyp von der veralteten, überholten, jedenfalls nicht mehr zeitgenössischen Glaubens- und Lebenshaltung, für die bei ihr das Alte Testament steht, auf bestimmte Männerbilder. So erklärt sie Jesus zum ersten Mann, ,der sich von dem, was man heute als toxische Männlichkeit bezeichnet, befreit hat. Er kam zu uns, die rauen Botschaften des Alten Testaments durch eine Liebesbotschaft zu ersetzen. Er trug die Haare lang und das Markenzeichen seiner Gesichtszüge ist bis heute diese männliche Weichheit. [...] Wer die Geschichte Jesu kennt, der wundert sich, wie heftig derzeit die Debatten über die neue Männlichkeit geführt werden. Hätte man die Botschaft Jesu ernst genommen, wäre der neue Mann schon mit dem Neuen 
Testament erfunden gewesen. Als männlich durchgesetzt haben sich jedoch Bilder der traditionellen Männlichkeit.“ (Marinić 2019).

Jesus steht demnach von seiner Erscheinung und seiner Botschaft her im Gegensatz zu seiner Umgebung, die dem Antiquierten verhaftet bleibt. Als „Neuer Mann“ befindet er sich im Gegensatz zu einem Kollektiv, das an den scheinbar veralteten „rauen Botschaften“ der alttestamentlichen Tradition klebt. Unausgesprochen bleibt, dass dieses Gegenüber mit seiner ,toxischen Männlichkeit“ jüdische Zeitgenossen Jesu waren. Trotz eines gewissen Augenzwinkerns geht Marinić anscheinend selbstverständlich davon aus, dass Jesus und das Neue Testament das Judentum mit seinen Traditionen und überkommenen Auffassungen vielfach infrage gestellt und die Härten und Grenzen des Alten Testaments überwunden habe. ${ }^{11}$ Sicherlich hat Jagoda Marinić diese Gegenübersetzung nicht vorgenommen, um das Judentum herabzuwürdigen. Gleichwohl zeigt ihre Argumentation, wie antijüdische Sprachmuster weiterhin im Gedächtnis abgespeichert sein und gegebenenfalls abgerufen werden können, auch ohne dass mit den sprachlichen Äußerungen irgendwelche antijüdische Absichten gemeint wären (vgl. Schwarz-Friesel und Reinharz 2013, S. 49f. und 113-115).

\subsection{Von der Beschneidungsdebatte und den Forderungen nach einem Schächtverbot bis zu Ritualmordlegenden}

Ein weiterer Schritt ist es, dieses Alte als archaisch oder grausam-unzeitgemäß zu deuten, wie es sich beispielsweise in den Debatten um spezifische religiöse Vorschriften von Islam und Judentum nachweisen lässt. Als vermeintlich aufgeklärter und rationaler, regelmäßig aber auch durch Ressentiments vergifteter Kampf für Kinder- und Tierrechte taucht diese Unterstellung nicht nur am rechten Rand der Gesellschaft auf, sondern auch in bürgerlichen Kreisen. Das belegen die Debatten um die rituelle Beschneidung von Knaben in der Folge eines Urteils des Kölner Landgerichts im Jahr 2012 und die betäubungsfreie rituelle Schlachtung von Tieren (vgl. UEA 2017; Zick et al. 2017). Den Schluss, dass eine gewisse Zahl nichtjüdischer Menschen über den Umweg der vermeintlichen Kritik an angeblich inhumanen religiösen Praktiken vorhandene antijüdische Ressentiments artikulieren, legen bereits einige Stichproben im Internet nahe (vgl. Schwarz-Friesel 2020, S. 61-65). Dabei handelt es sich um zeitgenössische Transformationen alter antijüdischer Denkmuster, die der eigenen Gruppe das Vernünftig-Human-Zeitgemäße zuschreiben und dem Judentum das Ritualistisch-Atavistisch-Grausame. In diesem Sinne verstanden auch verschiedene Philosophen der Aufklärung das ,Judentum“ als partikularistische Religion, die sich gegenüber dem Christentum bzw. der Vernunftreligion auf einem moralisch und rational niedrigeren Niveau befände (vgl. Nirenberg 2015; Eriksen 2020).

Ein Blick in die Bildtradition zeigt eine auffällige ikonografische Nähe mittelalterlicher Darstellungen der Beschneidung Jesu zur Abbildung von Ritualmordlegenden

\footnotetext{
11 Ähnliche Vorstellungen hatten in einer gewissen Phase des Feminismus der 1970er und 1980er-Jahre eine gewisse Konjunktur und werden bis heute von Publizisten wie Franz Alt (Jesus - der erste neue Mann) propagiert.
} 
(vgl. Heil 2006, S. 236). In beiden Fällen umringen Männer ein nacktes Kind und machen sich mit einem Messer an ihm zu schaffen (vgl. Schreckenberg 1996). Die Mythenbildung zu angeblichen „Ritualmorden“ und Knabenbeschneidungen lässt sich bis in die spätantike pagane Polemik gegen Judentum und Christentum zurückverfolgen und setzt sich bis in die Gegenwart fort (Tilly 2021). Ritualmordvorwürfe treten dann auch in innerchristlichen Polemiken gegen Häretiker auf, denen Vertreter der Rechtgläubigen unterstellten, sie hätten für ihre Eucharistie bzw. eucharistischen Elemente Kinder ermordet (vgl. Heil 2006, S. 238f.). An diese älteren Fassungen konnte die im 12. Jahrhundert erfolgte vergängnisvolle antijüdische Reformulierung von Ritualmordlegenden leicht anknüpfen. Die Bild- und Erzähltraditionen im späten Mittelalter steigerten das Gegenbild der Juden zu dämonischen Wesen und die Ritualmordlegenden zu Verschwörungserzählungen, die trotz aller Gegenrede und Verbote der Päpste regelmäßig Gehör fanden und Gewaltexzesse oder Todesurteile auslösten (vgl. Heil 2006; Erb 2010; Schwarz-Friesel 2020).

Abb. 2.

Abb. 3.

Bezüge zu dieser Bildtradition weist eine drastisch-derbe Karikatur aus der norwegischen Zeitung „Dagbladet“ aus Oslo vom Mai 2013 auf, die einen anscheinend religiös-rituell motivierten Gewaltakt an einem Baby abbildet. $\mathrm{Zu}$ sehen ist links ein bärtiger Mann mit Kopfbedeckung und einem Buch mit verziertem Einband, wie er - beim Rezitieren aus dem Buch - ein schreiendes, blutbespritztes und bereits mehrfach gestochenes Kind erneut mit einer Gabel verletzt. In der Mitte des Bildes ist eine Hand zu sehen, die eine Zehe des Kindes mit einer Gartenschere abschneidet. Daneben steht fröhlich die Mutter, die den herbeigerufenen Polizisten ein weiteres Buch mit verziertem Einband entgegenhält mit dem Kommentar: „Misshandlung? Nein, das ist Tradition und ein wichtiger Teil unseres Glaubens!“ Daraufhin antwortet der eine Polizist lächelnd: „Glaube? Ah so, dann ist alles in Ordnung!“ Und der andere ruft: „Entschuldigung für die Störung.“

Abb. 2 Darstellung der Ritualmordlegende des Simon von Trient. 1493. Holzschnitt von Michael Wolgemut in der Weltchronik von Hartmann Schedel, fol. 254v. Nürnberg: Anton Koberger. (http://mdz-nbnresolving.de/urn:nbn:de:bvb: 12-bsb00034024-1. Bildnummer 582. CC BY-NC-SA 4.0. Zugegriffen: 2. Dezember 2021)

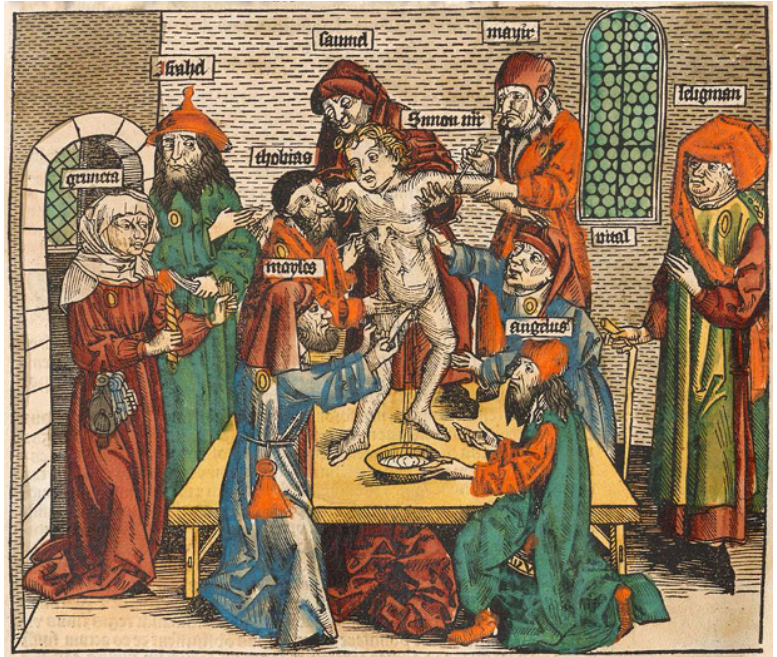




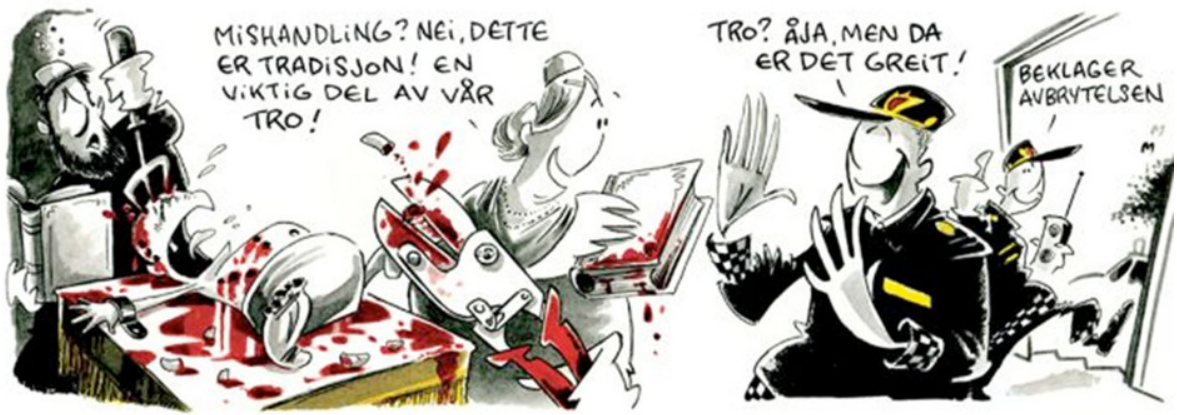

Abb. 3 Karikatur aus Dagbladet (Oslo) vom Mai 2013: Screenshot Jewish Women's Archive. Norwegian Circumcision Cartoon. Dagbladet (2013) (https://cdn.jwa.org/sites/default/files/mediaobjects/ 2349077637.jpg. Zugegriffen: 2. Dezember 2021)

Die Überschneidungen ihrer Karikatur mit den antijüdischen mittelalterlichen Bildtraditionen provozierten damals zahlreiche kritische Reaktionen, doch die Zeitungsredaktion verteidigte sich mit allgemeinen Hinweisen zu ihrem Recht auf Religionskritik. In einem Leitartikel vom 3. Juni 2013 machte sie das für politische Karikaturen genretypische Mittel der Übertreibung geltend und verwies darauf, dass sich der Zeichner keineswegs gegen die Praktiken einer bestimmten Religionsgruppe gerichtet habe. Vielmehr habe sich die Karikatur dagegen gewandt, dass Haltungen und Praktiken wie die rituelle Beschneidung unter dem Verweis auf Glaubensüberzeugungen von vornherein der Kritik und Diskussion entzogen seien (dagbladet.no. 2013).

\subsection{Traditionelle Muster in israelbezogenen Antisemitismen}

Wie wirksam traditionelle antijüdische Muster nach wie vor sind, zeigt sich auch in dem gegenwärtig besonders virulenten Feld von Wahrnehmungen und Bewertungen des Staates Israel bzw. seiner Politik im Blick auf den israelisch-palästinensischen Konflikt. Aktualisierte traditionelle antijüdische Denkmuster treten unter anderem in zwei Schriften des emeritierten renommierten Heidelberger Theologieprofessors Ulrich Duchrow aus den Jahren 2017 und 2019 zutage. Duchrow setzt sich seit vielen Jahren in seiner Lehre und Forschung unter anderem mit Befreiungstheologien und den theologischen Herausforderungen durch Kolonialismus und Ungleichheit auseinander. Seit einigen Jahren versteht er sich als Anwalt der vermeintlich verdrängten und verschwiegenen Leiderfahrungen der Palästinenser und engagiert sich dafür in führender Position beim ökumenischen Netzwerk Kairos Europa (vgl. Wiese 2019, S. 15-19). Dabei wirbt er bei christlichen Gruppen und kirchlichen Institutionen und Werken für ein Engagement bei dem internationalen Netzwerk „BDS“, dessen Aktivitäten er als gewaltfreien Widerstand gegen die völkerrechtswidrige Besatzung palästinensischen Landes für angemessen, ja sogar für geboten hält (Duchrow 2017).

Duchrows Argumentation ist durchzogen von dualen Wertungsmustern und verkürzt den Konflikt zwischen Israel und dem palästinensischen Volk letztlich auf ein Schwarz-Weiß-Schema, in dem Täter- und Opferrollen klar verteilt sind. Zwar 
beteuert er, dass es ihm und den Netzwerken, in denen er sich engagiert, um ein friedliches Zusammenleben von Juden, Moslems und Christen in „Palästina-Israel“ geht. Doch in allem geht er dabei von der Annahme aus, dass der Staat Israel und seine Politik bis heute unter einem Geburtsfehler litten: „Im westlichen Imperium ist der Staat Israel mit seiner gegenwärtigen Politik also ein weiteres Extrembeispiel der westlichen kolonialistischen, kapitalistischen, imperialen, wissenschaftlich-technischen, rassistischen, gewalttätigen Eroberungskultur, wie sie sich in den letzten 500 Jahren entfaltet hat.“ (Duchrow 2017, S. 179).

In seinem Aufsatz von 2017 mit dem Titel „Palästina/Israel als Beispiel von kolonialistischem Kapitalismus in theologischer Perspektive" fasste Duchrow seine Perspektive im Zeichen des Reformationsjubiläums zusammen. Unter Berufung auf die aus Petra Wilds Buch Apartheid und ethnische Säuberung in Palästina zustimmend zitierten Schlagworte „Apartheid, ethnische Säuberungen und schleichender Genozid" verortete Duchrow die israelische Palästinenserpolitik bei den Jugoslawienkriegen mit ihrem Tiefpunkt Srebrenica und dem rassistisch-autoritären Regime in Südafrika mit seiner programmatischen Rassentrennung. Doch ging er noch darüber hinaus: Während Südafrika ,ausbeuterisch und unterdrückerisch“ gewesen sei, verfolge Israel sogar das Ziel, ,die Menschen minderen Rechts komplett loszuwerden und die Übrigbleibenden zu Gettoisieren [sic!] wie Gaza“ (Duchrow 2017, S. 178).

Das Schlagwort von der „Gettoisierung“ knüpft sprachlich an die nationalsozialistischen Maßnahmen zur Vorbereitung der Schoah an und rückt den Staat Israel ausgerechnet an die Seite des nationalsozialistischen Deutschen Reiches. Dessen mörderischen Judenhass hatte Duchrow zwar als „das deutsche Verbrechen an den europäischen Juden“ in den Zusammenhang mit der judenfeindlichen christlichen Tradition gestellt und die theologische Aufarbeitung nach 1945 als ,,unbedingt geboten“ bezeichnet (2017, S. 168). Im Kontext seiner weiteren Ausführungen wirkt dieses Bekenntnis jedoch eher wie eine rhetorische Pflichtübung. Seine Schlussfolgerung aus der Schoah besteht anscheinend darin, an die Notwendigkeit zur Orientierung an den Menschenrechten und zur Befreiung von kapitalistischen, kolonialistischen, imperialen Strukturen zu appellieren. Bei näherem Hinsehen erweist sich das als Aktualisierung traditioneller antijüdischer Projektionen: Der Staat Israel fungiert in der Art und Weise seiner Existenz als geradezu paradigmatische Gegenwirklichkeit zu Duchrows Forderungen und Idealen. Unter dieser Feindbildkonstruktion leidet die gründliche Analyse des Konflikts an der südlichen Levante ebenso, wie sie von der Frage nach den richtigen Konsequenzen aus der Schoah hier in Deutschland, mithin um die moralisch aufgeladene Frage nach dem Selbstverständnis der Deutschen nach der Schoah, überlagert wird (vgl. EAD 2019, S. 25-27).

Der 2017 publizierte Beitrag Duchrows zum Reformationsjubiläum war auf scharfe Kritik gestoßen. Im Jahr 2019 rechtfertigte der Verfasser seine Position in einem Vortrag vor dem „Protestantischen Club der Evangelischen Akademikerschaft“ im pfälzischen Neustadt, den der ,Evangelische Kirchenbote - Sonntagsblatt für die Pfalz" in seiner Ausgabe vom 23. August in einer gekürzten Fassung veröffentlichte (Duchrow 2019). In diesem Artikel kommt noch deutlicher zum Ausdruck, dass die Frage nach der Identität der deutschen Gesellschaft und der Bewältigung der deutschen Schuld bei Duchrow eine zentrale Rolle spielt. 
Den Umstand, dass insbesondere die Kirchenleitungen andere Konsequenzen als er zogen und er Kritik erfuhr, erklärte er mit einer Erzählung, die Elemente von judenfeindlichen Verschwörungsvorstellungen enthält: Demnach seien die Kirchenleitungen nicht nur durch den christlich-jüdischen Dialog in ihrer Wahrnehmungsfähigkeit des israelisch-palästinensischen Konflikts beeinträchtigt. Sie würden außerdem auch ,,verhindern, dass kritische Stimmen zu den Völkerrechts- und Menschenrechtsverbrechen des Staates Israel zu Wort kommen“ (Duchrow 2019). Bereits 2017 hatte er diese Sichtweise der offiziellen Kirche mit Schuldgefühlen und „Loyalität mit ihren z. T. unkritischen jüdischen Gesprächspartnern“ erklärt (Duchrow, 2017, S. 197). 2019 spitzte er den Gegensatz in der deutschen Debatte geradezu apokalyptisch zu, indem er im Anschluss an den US-amerikanischen, ,jüdische[n] Befreiungstheologe[n] Marc Ellis“ den ,,prophetischen“ Juden und Christen sogenannte ,konstantinische“ Juden und Christen gegenüberstellte. Die erste Gruppe, der er auch sich selbst zurechnete, weise in der Nachfolge der biblischen Propheten und Jesu auf das Unrecht hin, das der Staat Israel den Palästinensern antut. Die zweite Gruppe, der er die Kirchenleitungen und ihre jüdischen Dialogpartnerinnen zurechnete, betreibe ihren Dialog auf Kosten der Palästinenser und verbünde sich ,mit politischen und ökonomischen Mächten“ (Duchrow 2019).

Diesem Muster folgte die antijüdische christliche Polemik in ihrem Umgang mit der Bibel bereits seit der Alten Kirche: Als Adressaten der prophetischen Kritik galten ausschließlich die jüdischen Zeitgenossen, während die christliche Kirche exklusiv als Adressatin der Heilsankündigungen verstanden wurde. „Wir haben es nicht einfach nur mit einer Vereinnahmung des Alten Testaments zu tun, sondern mit einer gespaltenen Nutzanwendung. “ (Meiser 2015) Dem eigenen Anspruch, das verhängnisvolle judenfeindliche Denken zu überwinden und gerade keine Feindbilder konstruieren zu wollen, kann Duchrow mit diesem Ansatz nicht gerecht werden. Uneingelöst bleibt das Versprechen, das der von ihm mitherausgegebene Sammelband von 2017 im Untertitel formulierte: ,Jenseits von Luthers Feindbildern“. Vielmehr knüpfte er mit seiner Rede von ,,prophetischen“ und „,konstantinischen“ Juden und Christen geradezu frappierend unmittelbar an Martin Luther an. 1543 erklärte der Wittenberger Reformator in seiner Schrift „Von den Juden und ihren Lügen“, warum die gegenwärtigen, die „kaiserischen“ Juden nichts mit den biblischen, den „mosaischen“ Juden gemein hätten. Die einen waren für ihn gesetzlos, zerstreut und ohne Heilsperspektive, die anderen gewissermaßen die rechtgläubigen, gesetzestreuen Vorläufer der Christen mit einer heilvollen Perspektive: „Es gibt zweierlei Juden oder [zweierlei] Israel. Die ersten sind [die Juden], die Mose aus Ägypten ins Land Kanaan führt, wie ihm Gott befohlen hatte. Diesen [Juden] gab er sein Gesetz, das sie in diesem Lande halten sollten - nur solange, bis der Messias käme. Die anderen Juden sind die Juden des Kaisers, nicht Moses Juden. Die haben zur Zeit des Pilatus, des Landpflegers im Lande Juda, angefangen. [...] Von denen ist der jetzige übrige Rest der Juden, von denen Mose nichts weiß. Sie selbst [wissen] von ihm auch nichts, denn sie halten keinen Passuk oder Vers im [Buch des ] Mose." (zit. n. Morgenstern 2016, S. 200).

Gewiss verweisen die kaiserlichen und mosaischen Juden Luthers auf andere Ziele als die konstantinischen und prophetischen Juden und Christen Duchrows: Luther wollte den bestehenden minderen Rechtsstatus der Juden theologisch begründet ver- 
schärfen, um das christliche Gemeinwesen zu stabilisieren, wie er meinte. Zudem wollte er das rechte Verständnis der Bibel und ihre Verheißungen ausschließlich für die Christen reklamieren. Duchrows Verweis auf biblische Traditionen und prophetische Kritik zielte dagegen darauf, die eigene Deutung der Entstehung, Geschichte und Politik des Staates Israel gegen Kritik zu immunisieren und den „offiziellen“ christlich-jüdischen Dialog als Konsequenz eines Schoah-bedingten Schuldkomplexes und ,,jüdischer" Manipulation zu delegitimieren. Duchrow leitete aus der Schoah den moralischen Imperativ ab, sich für Menschen- und Völkerrecht zugunsten der Palästinenser zu engagieren und zugleich Fundamentalkritik an Entstehung und Politik des Staates Israel zu üben. Doch führt diese einseitige Perspektive gerade nicht zu einer selbstkritischen Überwindung der antijüdischen Tradition, sondern schreibt deren Voraussetzungen, Denkmuster und Feindbildprojektionen in aktualisierter Form fort. Unter dieser Prämisse bleiben sowohl Duchrows Appelle zur Abkehr von der christlichen Judenfeindschaft zugunsten der Gerechtigkeit in „Palästina-Israel“ - immer in dieser Reihenfolge - und sein Verweis auf das im UN-Teilungsbeschluss von 1947 völkerrechtliche verbriefte Existenzrecht des Staates Israel kaum mehr als ein Lippenbekenntnis.

\section{Schluss}

Die genannten Beispiele zeigen, dass die Grundstrukturen judenfeindlichen Denkens mit ihren dualen Wertungsmustern, die die christliche antijüdische Propaganda über die Jahrhunderte hinweg verbreitet hat, weiterhin anpassungsfähig und tragfähig sind. Christhard Hoffmann hat 1990 in seinem nach wie vor sehr lesenswerten Aufsatz „Das Judentum als Antithese. Zur Tradition eines kulturellen Wertungsmusters“ die Nachwirkungen der christlichen Judenfeindschaft und deren jeweilige ,Vorzeichenwechsel“ analysiert. Er urteilte damals optimistisch, „daß die Dynamik des traditionellen Antijudaismus nach 1945 im Wesentlichen gebrochen worden ist. Das alte Wertungsmuster, welches das „Judentum“ als Antithese für jedes gegenwärtige Übel, das überwunden werden muß, auffaßte, wird zwar gelegentlich [...] aufgegriffen, es hat seine öffentliche Wirksamkeit und Überzeugungskraft aber weitgehend verloren." (Hoffmann 1990, S. 34) Hoffmann hat damit nicht recht behalten. Gewiss geht es heute eher selten um explizit religiöse Konflikte. Wohl aber wirken christlich geprägte - antijudaistische - Denkmuster weiter fort, gerade auch in der digitalen Öffentlichkeit. Nach wie vor sind sie anscheinend weiterhin so plausibel und bieten ein nach wie vor genutztes Reservoir, sodass auch etliche Menschen des 21. Jahrhunderts sie bewusst nutzen oder unbewusst und ungewollt reproduzieren, manchmal auch aktualisieren und fortschreiben.

Funding Open Access funding enabled and organized by Projekt DEAL.

Open Access Dieser Artikel wird unter der Creative Commons Namensnennung 4.0 International Lizenz veröffentlicht, welche die Nutzung, Vervielfältigung, Bearbeitung, Verbreitung und Wiedergabe in jeglichem Medium und Format erlaubt, sofern Sie den/die ursprünglichen Autor(en) und die Quelle ordnungsgemäß nennen, einen Link zur Creative Commons Lizenz beifügen und angeben, ob Änderungen vorgenommen wurden. 
Die in diesem Artikel enthaltenen Bilder und sonstiges Drittmaterial unterliegen ebenfalls der genannten Creative Commons Lizenz, sofern sich aus der Abbildungslegende nichts anderes ergibt. Sofern das betreffende Material nicht unter der genannten Creative Commons Lizenz steht und die betreffende Handlung nicht nach gesetzlichen Vorschriften erlaubt ist, ist für die oben aufgeführten Weiterverwendungen des Materials die Einwilligung des jeweiligen Rechteinhabers einzuholen.

Weitere Details zur Lizenz entnehmen Sie bitte der Lizenzinformation auf http://creativecommons.org/ licenses/by/4.0/deed.de.

\section{Literatur}

Bergmann, Werner. 2010. Sekundärer Antisemitismus. In Handbuch des Antisemitismus. Judenfeindschaft in Geschichte und Gegenwart, Bd. 3, Hrsg. Wolfgang Benz, 300-302. Berlin, New York: de Gruyter.

Blum, Matthias. 2010a. Exegese. In Handbuch des Antisemitismus. Judenfeindschaft in Geschichte und Gegenwart, Bd. 3, Hrsg. Wolfgang Benz, 80-83. Berlin, New York: de Gruyter. [zit. Blum 2010a].

Blum, Matthias. 2010b. Gottesmord. In Handbuch des Antisemitismus. Judenfeindschaft in Geschichte und Gegenwart, Bd. 3, Hrsg. Wolfgang Benz, 113-114. Berlin, New York: de Gruyter. [zit. Blum 2010b].

Blum, Matthias. 2011. Passionsspiele. In Handbuch des Antisemitismus. Judenfeindschaft in Geschichte und Gegenwart, Bd. 4, Hrsg. Wolfgang Benz, 263-265. Berlin, New York: de Gruyter.

Brändle, Rudolf, und Verena Jegher-Bucher. 1995. Johannes Chrysostomus. Acht Reden gegen die Juden. Stuttgart: Hiersemann.

Brändle, Rudolf, und Wendy Pradels. 2008. „Boshaft wie goldene Rede“. Aspekte der Traditions- und Rezeptionsgeschichte der Reden gegen die Juden von Johannes Chrysostomus. In Chrysostomusbilder in 1600 Jahren. Facetten der Wirkungsgeschichte eines Kirchenvaters, Hrsg. Martin Walraff, Rudolf Brändle, 235-254. Berlin, New York: de Gruyter.

Dagbladet. 2013. Dagbladet and Antisemitism. https://www.dagbladet.no/kultur/dagbladet-andantisemitism/60227099 (Erstellt: 21. Okt. 2016). Zugegriffen: 2. Dez. 2021.

Detmers, Achim. 2001. Reformation und Judentum. Israel-Lehren und Einstellungen zum Judentum von Luther bis zum frühen Calvin. Stuttgart: Kohlhammer.

Detmers, Achim. 2002. Vom „Judaismus“ zum „Antijudaismus“. In Judentum und Christentum zwischen Konfrontation und Faszination, Hrsg. Wolfram Kinzig, Cornelia Kück, 75-95. Stuttgart: Kohlhammer.

Duchrow, Ulrich. 2017. Palästina/Israel als Beispiel von kolonialistischem Kapitalismus in theologischer Perspektive. In Religionen für Gerechtigkeit in Palästina/Israel. Jenseits von Luthers Feindbildern, Hrsg. Ulrich Duchrow, Hans G. Ulrich, 166-202. Berlin: Lit.

Duchrow, Ulrich. 2019. Befreiung von Besatzung auch Befreiung für Israel. Wir wir als Deutsche Israelis und Palästinensern gerecht werden können - Ein Plädoyer für mehr Ehrlichkeit im Dialog. Evangelischer Kirchenbote der Pfalz (23. August 2019). https://www.kirchenbote-online.de/ artikel/detailansicht/news/befreiung-von-besatzung-auch-befreiung-fuer-israel/. Zugegriffen: 26. Nov. 2021.

Enzenbach, Isabel. 2018. Antisemitismus in der zeitgenössischen Karikatur. Das Beispiel der Netanjahu/ Netta-Zeichnung in der „Süddeutschen Zeitung“, Visual History. https://doi.org/10.14765/zzf.dok.5. 1321. Zugegriffen: 26. Nov. 2021.

Erb, Rainer. 2010. Ritualmordbeschuldigung. In Handbuch des Antisemitismus. Judenfeindschaft in Geschichte und Gegenwart, Bd. 3, Hrsg. Wolfgang Benz, 293-294. Berlin, New York: de Gruyter.

Eriksen, Trond Berg. 2020. Die Schattenseiten von Aufklärung und Romantik. In Judenhass. Die Geschichte des Antisemitismus von der Antike bis zur Gegenwart, Hrsg. Trond Berg Eriksen, et al., 139-159. Göttingen: Vandenhoeck \& Ruprecht.

Evangelische Akademien in Deutschland. 2019. Antisemitismus und Protestantismus. Impulse zur Selbstreflexion. https://www.evangelische-akademien.de/publikation/antisemitismus-und-protestantismusimpulse-zur-selbstreflexion/. Zugegriffen: 26. Nov. 2021. [zit. EAD 2019].

Friedländer, Saul. 1998. Die Jahre der Verfolgung 1933-1939. Das Dritte Reich und die Juden, Bd. 1. München: C. H. Beck.

Gailus, Manfred, und Clemens Vollnhals (Hrsg.). 2020. Christlicher Antisemitismus im 20. Jahrhundert. Der Tübinger Theologe und „Judenforscher" Gerhard Kittel. Göttingen: V \& R unipress. 
Harket, Håkon. 2019. Die Dreyfus-Affäre und der französische Antisemitismus. In Judenhass. Die Geschichte des Antisemitismus von der Antike bis zur Gegenwart, Hrsg. Trond Berg Eriksen, et al., 365-381. Göttingen: Vandenhoeck \& Ruprecht.

Heil, Johannes. 2006. „Gottesfeinde“ - „Menschenfeinde“. Die Vorstellung von jüdischer Weltverschwörung (13. bis 16. Jahrhundert). Essen: Klartext.

Heil, Johannes. 2015. Das unsichtbare Kollektiv und der gesichtslose Henker. In Bilder kollektiver Gewalt. Kollektive Gewalt im Bild. Annäherungen an eine Ikonographie der Gewalt. Festschrift Werner Bergmann, Hrsg. Michael Kohlstruck, et al., 345-355. Berlin: Metropol.

Heil, Johannes. 2017. Die Bürde der Geschichte: Stationen der langlebigen „Lehre der Verachtung“. In Hin zu einer Partnerschaft zwischen Juden und Christen. Die Erklärung orthodoxer Rabbiner zum Christentum, Hrsg. Jehoschua Ahrens, et al., 26-52. Berlin: Metropol.

Hoffmann, Christhard. 1990. Das Judentum als Antithese. Zur Tradition eines kulturellen Wertungsmusters. In Antisemitismus in der politischen Kultur nach 1945, Hrsg. Werner Bergmann, Rainer Erb, 20-38. Opladen: Westdeutscher Verlag.

Holz, Klaus. 2001. Nationaler Antisemitismus. Wissenssoziologie einer Weltanschauung. Hamburg: Hamburger Edition.

Holz, Klaus. 2017. Säkularer Antisemitismus als politische Theologie. epd-Dokumentation 17:4-11.

Junginger, Horst. 2011. Die Verwissenschaftlichung der „Judenfrage“ im Nationalsozialismus. Darmstadt: Wissenschaftliche Buchgesellschaft.

Kampling, Rainer. 2010a. Antijudaismus. In Handbuch des Antisemitismus. Judenfeindschaft in Geschichte und Gegenwart, Bd. 3, Hrsg. Wolfgang Benz, 10-13. Berlin, New York: de Gruyter. [zit. Kampling 2010a].

Kampling, Rainer. 2010b. Art. Substitutionslehre. In Handbuch des Antisemitismus. Judenfeindschaft in Geschichte und Gegenwart, Bd. 3, Hrsg. Wolfgang Benz, 310-312. Berlin, New York: de Gruyter. [zit. Kampling 2010b].

Kaufmann, Thomas. 2011. Luthers „Judenschriften“. Ein Beitrag zu ihrer historischen Kontextualisierung. Tübingen: Mohr Siebeck.

Kaufmann, Thomas. 2014. Luthers Juden. Stuttgart: Ph. Reclam.

Kinzig, Wolfram. 2002. Nähe und Distanz. Auf dem Weg zu einer neuen Beschreibung der jüdisch-christlichen Beziehungen. In Judentum und Christentum zwischen Konfrontation und Faszination. Ansätze zu einer neuen Beschreibung der jüdisch-christlichen Beziehungen, Hrsg. Wolfram Kinzig, Cornelia Kück, 9-27. Stuttgart: Kohlhammer.

Kirn, Hans-Martin. 2017. Die spätmittelalterliche Kirche und das Judentum. In Protestantismus, Antijudaismus, Antisemitismus, Hrsg. Dorothea Wendebourg, et al., 3-23. Tübingen: Mohr Siebeck.

Lange, Matthew. 2010. Bankjude. In Handbuch des Antisemitismus. Judenfeindschaft in Geschichte und Gegenwart, Bd. 3, Hrsg. Wolfgang Benz, 40-42. Berlin, New York: de Gruyter.

Lindemann, Gerhard. 2020. Gerhard Kittel: familiäre Herkunft, Ausbildung und wissenschaftliche Anfänge. In Christlicher Antisemitismus im 20. Jahrhundert. Der Tübinger Theologe und „Judenforscher“ Gerhard Kittel, Hrsg. Manfred Gailus, Clemens Vollnhals, 63-82. Göttingen: V \& R unipress.

Lobermeier, Olaf, Jana Klemm, und Rainer Strobl. 2016. Abschlussbericht Kirchenmitgliedschaft und politische Kultur. Ausprägungen von Elementen Gruppenbezogener Menschenfeindlichkeit unter Mitgliedern der evangelischen Kirche. http://static.evangelisch.de/get/?daid= 2AKoRM44M1IUdBP5am4slshL00158249\&dfid=download. Zugegriffen: 2. Dez. 2021.

Marinić, Jagoda. 2019. Männer, warum stemmt ihr euch gegen ein moderneres Rollenbild? Süddeutsche Zeitung vom 21. April 2019.

Meiser, Martin. 2015. Rechtfertigungslehre und Antijudaismus - Paulus und Luther im Vergleich. https:// pfarrerblatt.de/prof-dr-martin-meiser/rechtfertigungslehre-und-antijudaismus/. Zugegriffen: 2. Dez. 2021.

Migne, Jacques-Paul. 1862. Patrologiae Graecae. tomus XLVII. S. Joannes Chrysostomus., 813-837. Paris: J.-P. Migne.

Morgenstern, Matthias. 2016. Martin Luther. Von den Juden und ihren Lügen. Neu bearbeitet und kommentiert. Berlin: Berlin University Press.

Nirenberg, David. 2015. Anti-Judaismus. Eine andere Geschichte des westlichen Denkens. München: C. H. Beck.

Reinbold, Wolfgang. 2013. Jesus und die Rabbinen. In Handbuch des Antisemitismus. Judenfeindschaft in Geschichte und Gegenwart, Bd. 6, Hrsg. Wolfgang Benz, 306-308. Berlin, New York: de Gruyter.

Rendtorff, Rolf, und Hans Hermann Henrix (Hrsg.). 1988. Die Kirchen und das Judentum. Dokumente von 1945 bis 1985. Paderborn, München: Bonifatius und Chr. Kaiser. 
RIAS Bayern. 2021. „Das muss man auch mal ganz klar benennen dürfen“. Verschwörungsdenken und Antisemitismus im Kontext von Corona. https://report-antisemitism.de/documents/RIAS_Bayern_ Monitoring_Verschwoerungsdenken_und_Antisemitismus_im_Kontext_von_Corona.pdf. Zugegriffen: 2. Dez. 2021.

Ritter, Adolf Martin. 2017. Judentum und Christentum zwischen Konfrontation und Faszination. Das Zeugnis des Johannes Chrysostomus und Augustins. In Judentum und Antisemitismus in Europa, Hrsg. Ulrich A. Wien, 25-56. Tübingen: Mohr Siebeck.

Schäfer, Peter. 2020. Kurze Geschichte des Antisemitismus. München: C. H. Beck.

Scherr, Albert. 2011. Expertise: Verbreitung von Stereotypen über Juden und antisemitischer Vorurteile in der evangelischen Kirche. https://bagkr.de/wp-content/uploads/2018/07/scherr_AS-in-der-evKirche.pdf. Zugegriffen: 2. Dez. 2021.

Schreckenberg, Heinz. 1982. Die christlichen Adversus-Judaeos-Texte und ihr literarisches und historisches Umfeld (1.-11. Jh.). Frankfurt a.M., Bern: Peter Lang.

Schreckenberg, Heinz. 1996. Die Juden in der Kunst Europas. Ein historischer Bildatlas. Göttingen und Freiburg: Vandenhoeck \& Ruprecht, Herder.

Schüler-Springorum, Stefanie. 2018. Antijudaismus/Antisemitismus. In Handbuch Jüdische Studien, Hrsg. Christina von Braun, Micha Brumlik, 363-369. Wien: Böhlau.

Schwarz-Friesel, Monika. 2020. Judenhass im Internet. Antisemitismus als kulturelle Konstante und kollektives Gefühl. Bonn: bpb.

Schwarz-Friesel, Monika, und Jehuda Reinharz. 2013. Die Sprache der Judenfeindschaft im 21. Jahrhundert. Berlin, Boston: de Gruyter.

Spichal, Jutta. 2015. Vorurteile gegen Juden im christlichen Religionsunterricht. Eine qualitative Inhaltsanalyse ausgewählter Lehrpläne und Schulbücher in Deutschland und Österreich. Göttingen: $\mathrm{V} \& \mathrm{R}$ unipress.

Tilly, Michael. 2021. Von Apion zu QAnon. Alte Verschwörungstheorien in neuem Gewand. Welt und Umwelt der Bibel 99:62-63.

Töllner, Axel. 2020. Bayerische Stimmen zum christlich-jüdischen Verhältnis aus den Jahren um 1950. In Tempel. Lehrhaus, Synagoge. Orte jüdischen Lernens und Lebens. Festschrift für Wolfgang Kraus, Hrsg. Christian Eberhard, et al., 423-436. Paderborn: F. Schöningh.

Treß, Werner. 2018. Jüdisches Gesetz und Staatsbürgerrecht im Übergang zur Moderne. In Handbuch Jüdische Studien, Hrsg. Christina von Braun, Micha Brumlik, 335-350. Wien: Böhlau.

Unabhängiger Expertenkreis Antisemitismus. 2011. Antisemitismus in Deutschland - Erscheinungsformen, Bedingungen, Präventionsansätze. Hrsg. Bundesministerium des Innern. Berlin. https://www. bmi.bund.de/SharedDocs/downloads/DE/publikationen/themen/heimat-integration/expertenkreisantisemitismus/antisemitismus-in-deutschland-bericht.pdf. Zugegriffen: 2. Dez. 2021. [zit. UEA 2011].

Unabhängiger Expertenkreis Antisemitismus. 2017. Antisemitismus in Deutschland - aktuelle Entwicklungen. Hrsg. Bundesministerium des Innern, für Bau und Heimat. Berlin. https://www.bmi.bund.de/ SharedDocs/downloads/DE/publikationen/themen/heimat-integration/expertenkreis-antisemitismus/ expertenbericht-antisemitismus-in-deutschland.html. Zugegriffen: 2. Dez. 2021. [zit. UEA 2017].

Wiese, Christian. 2017. Politische Dimensionen des Theologischen: Christentum und Antisemitismus im 20. Jahrhundert. epd-Dokumentation 17:26-37.

Wiese, Christian. 2019. Antisemitismus in der Evangelischen Theologie und Kirche. Expertise für den 2. Unabhängigen Expertenkreis Antisemitismus (Stand 14.11.2019). https://www.bmi.bund.de/ SharedDocs/downloads/DE/veroeffentlichungen/themen/heimat-integration/antisemitismus/ antisemitismus-expertisen.pdf?_blob=publicationFile\&v=4. Zugegriffen: 2. Dez. 2021.

Zick, Andreas, et al. 2017. Jüdische Perspektiven auf Antisemitismus in Deutschland. Ein Studienbericht für den Expertenrat Antisemitismus. Bielefeld. https://archive.jpr.org.uk/download?id=4592. Zugegriffen: 2. Dez. 2021. 